\title{
On the Significance of Concentrated Solar Power R\&D in Sweden
}

\author{
Torsten Strand $^{1 *}$, James Spelling ${ }^{1}$, Björn Laumert ${ }^{1}$, Torsten Fransson ${ }^{1}$ \\ ${ }^{I}$ Department of Energy Technology, KTH Royal Institute of Technology, Stockholm, Sweden \\ *Corresponding Author.Tel : +46 70268 4024,E-mail : torsten.strand@punkt.se
}

\begin{abstract}
Concentrated Solar Power (CSP) is an emerging renewable energy technology that has the potential to provide a major part of European energy needs at competitive cost levels. Swedish industry is strongly involved in CSP-based energy production either in the form of growing providers on the European energy market or as developers and producers of key components for CSP power plants. The growing industrial interest is reflected and accompanied by state of the art research in this field at the Department of Energy Technology at KTH. In the present paper the main challenges and opportunities for CSP R\&D are presented and linked to the industrial environment and interests in Sweden. Related to these challenges, an overview of the latest research activities and results at the Department of Energy Technology is given with examples concerning CSP plant operation and optimisation, technoeconomic cycle studies and high temperature solar receiver development.
\end{abstract}

Keywords: solar thermal power, Sweden, research and development

\section{Nomenclature}

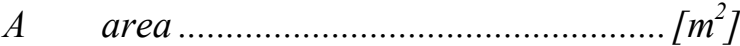

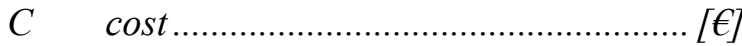

DNI Direct Normal Irradiation

E electrical energy ......................... $[\mathrm{kWh}]$

$i \quad$ interest rate ....................................... [ - ]
$I_{o} \quad$ incident solar flux ...................... $\left[\mathrm{W} / \mathrm{m}^{2}\right]$

LEC Levelised Electricity Cost.......... [€/kWh $]$

n payback time................................. [years]

$\alpha \quad$ annualisation factor ........................... [ - ]

$\varepsilon \quad$ efficiency........................................... [-]

\section{Introduction}

At first glance, concentrated solar power (CSP) may not seem of great interest to Sweden, which receives only weak solar irradiation with few sunny days in winter when power is needed most. However, seen from the wider perspective of a sustainable energy system, with input from many different energy sources (such as hydro, wind and biomass) across Europe, North Africa and parts of Middle East, CSP could form a dominating part of the solution to future energy shortages and the problem of rising $\mathrm{CO}_{2}$ emissions [1].

Sweden is today increasingly integrated in the European energy grid and major Swedish providers (e.g. Vattenfall, Fortum, E.ON) are growing on the continental energy market. Furthermore, many Swedish companies (e.g. Siemens Industrial Turbomachinery, ABB) are actively involved in the production of components for CSP plants such as steam turbines, mirrors for the collector fields and many more. As such, Sweden's interest in CSP is due not only to its wider environmental credentials, but also its direct economic importance to the country. There is thus good reason for Swedish energy institutions, authorities, industry and universities to actively take part in development to further strengthen the established position in this field.

\section{Concentrated Solar Power Technology}

In its most basic form, a CSP plant consists of solar collector field with mirrors that concentrate the solar radiation to one or more receivers where this radiation is converted to high temperature heat [2]. This high temperature heat source can be used to drive conventional power generation 
equipment (such as steam cycles, Stirling engines, micro gas-turbines, etc.) to produce electricity. Significant amounts of waste heat are also available which are currently wasted but could be used to drive other processes.

The levelised cost of electricity (LEC) of CSP-based power plants has been shown to be amongst the most competitive of all renewable energy technologies [3], with a significant cost advantage over PV when deployed on a large scale. However, CSP technology has not yet matured to the point of grid-parity with conventional power generation systems, although this is predicted to occur within the next 15 years [4]. Rapid reductions in the LEC of CSP-based systems are expected, as shown in Table 1, whereas the cost of fossil-fuel based power is expected to rise with increased fuel prices and the introduction of $\mathrm{CO}_{2}$ cap-and-trade schemes.

Table 1. Current and Predicted LEC of Selected Power Generation Technologies [4], [5]

\begin{tabular}{cccccc}
\hline $\begin{array}{c}\text { LEC } \\
{\left[€ \mathrm{cts} / \mathrm{kWh}_{\mathrm{e}}\right]}\end{array}$ & $\begin{array}{c}\text { Parabolic } \\
\text { Trough }\end{array}$ & $\begin{array}{c}\text { Solar Power } \\
\text { Tower }\end{array}$ & $\begin{array}{c}\text { Dish } \\
\text { Stirling }\end{array}$ & Solar PV & Coal \\
\hline Current $(2010)$ & 17.2 & 24.1 & 28.1 & 28.4 & 8.4 \\
Future $(2025)$ & 12.8 & 9.7 & 14.0 & 14.8 & 10.8 \\
\hline
\end{tabular}

Direct solar irradiation is an abundant renewable energy source [1] but is available only at low flux densities: large areas must be used to collect enough energy. Even so, the area necessary to satisfy all of Europe's electricity needs using currently available CSP technology would be only a small fraction of the North African deserts [1]. The most suitable areas for CSP deployment are within the tropics, where irradiation is good, almost all days are cloudless and the land is of desert type with low population [3]. Suitable areas for CSP are shown in Fig. 1.

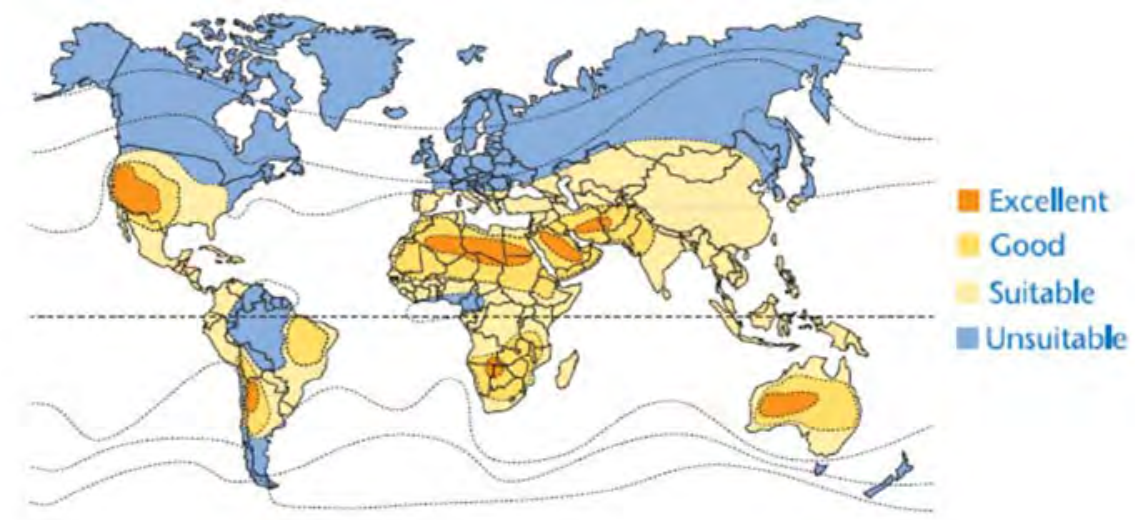

Fig. 1. Distribution of Sites Suitable for Solar Thermal Power Production Source: German Aerospace Centre (DLR)

In Europe the requirements for economic electricity production with CSP are fulfilled for a number of countries around the Mediterranean Sea but the real "European Sun-belt" is in North Africa. A group of leading European industries have established the DESERTEC foundation [1] for promoting the deployment of CSP-technology in the North-African deserts, with the stated aim of providing $15 \%$ of the European electricity requirements [1], as well as meeting local demand. The total investment in CSP plants and transmission lines is expected to be in the region of $€ 400$ billion, to be realised by 2050 . 


\subsection{Conventional CSP Technology}

The dominating CSP technology: linear parabolic trough mirrors with collectors producing steam for conventional steam turbine plants, as shown to the left of Fig. 2, has been commercial for about 30 years [4]. The power range for these systems has been $30-80 \mathrm{MW}_{\mathrm{e}}$ with solar-electric efficiency around $15-20 \%$ [2]. A high number of $50 \mathrm{MW}_{\mathrm{e}}$ plants of that type are presently being put into operation in Spain [5]. Plants in the power range of $400 \mathrm{MW}_{\mathrm{e}}$ are built in the USA and planned for North Africa. Currently almost all steam turbines for solar thermal power plants are delivered from Sweden by Siemens Industrial Turbomachinery.

The technology is well proven and the present development trends are:

- Higher turbine inlet temperatures by developing heat transfer media with the ability to withstand higher temperatures

- Extension of operating time by hybrid operation, energy storage and shorter start-up times

- Efficiency improvements on mirrors and receiver pipes by optimised glass qualities and surface coatings

The cost break down of such a plant shows that the solar field is the most costly part, around $50 \%$ and that the thermal conversion unit is only around $24 \%$ [4].

\subsection{Solar Towers: the Emerging Technology}

Solar towers surrounded by heliostats, as shown to the right of Fig. 2, have higher solar concentration factors than parabolic troughs and can thus reach higher temperatures [2]. The size of the heliostat field around a tower has an optimum determined mainly by the height of the tower and the losses from the most distant mirrors. Today the optimal thermal power from a tower seems to be around $100 \mathrm{MW}_{\text {th }}$ with a $160 \mathrm{~m}$ tower and some 830 heliostats with a $121 \mathrm{~m}^{2}$ mirror area per unit [5]. Larger systems can be expected considering possible advancement in mirror and receiver efficiencies and control system precision.
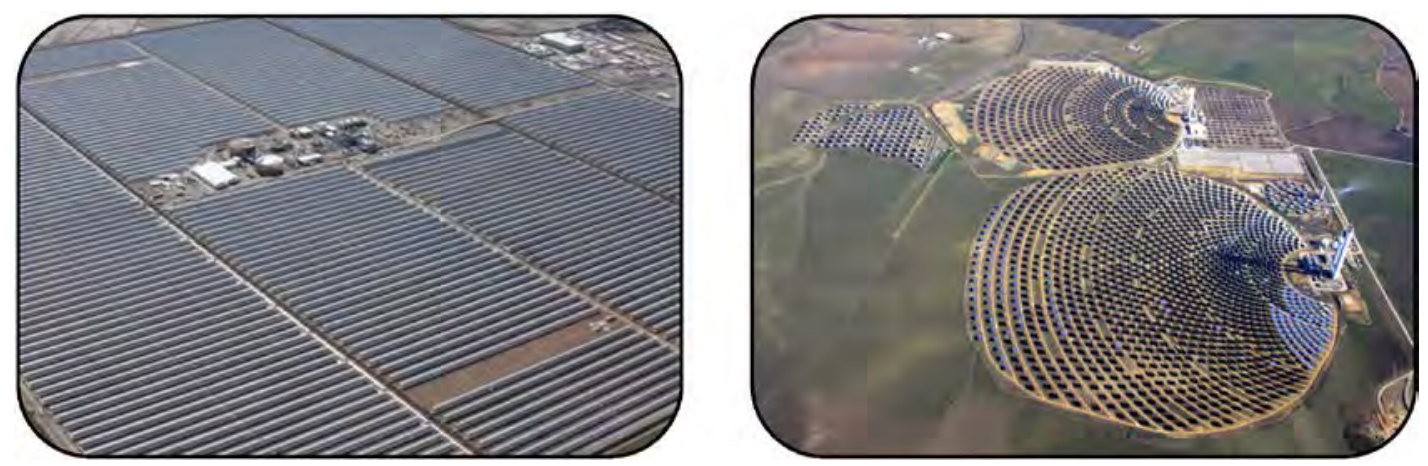

Fig. 2. Conventional (left) and Emerging (right) CSP Technology Source: Solar Millennium/Abengoa Solar

Presently the receivers are placed on top of the tower, which means the heat has to be transported by some means to the power block on the ground down the height of the tower. For small size units (up to around $6 \mathrm{MW}_{\mathrm{e}}$ ) the power generation unit could be placed at the top of the tower, close to the receivers. The tower arrangement can be used with steam turbines, providing higher 
live steam temperatures than the parabolic trough solar fields. More interesting is that gasturbines can also be considered for the conversion of heat to electricity. Gas-turbines are cheaper, simpler to install, potentially more efficient and do not need water.

\section{Challenges and Opportunities in CSP R\&D}

CSP remains an emerging technology, with an active R\&D community working to improve the viability and effectiveness of the concept. On-going research activities at the Department of Energy Technology (EGI) of the Royal Institute of Technology, Stockholm have highlighted what the authors believe to be some key challenges in the development and deployment of CSP technology at the current time.

\subsection{Increasing Economic Competitiveness}

Solar thermal power technology cannot yet be considered to be directly competitive with conventional power generation technology (such as those based on the combustion of coal or natural gas) but later most probably with new nuclear power. In the current energy market, deployment of CSP technology is supported by government incentives such as feed-in tariffs and loan guarantees. Increasing the competitiveness of CSP technology is a key challenge in solar R\&D and will go hand-in-hand with increased CSP deployment [2]. As such, any reduction in the cost of this technology represents a major opportunity for the industry.

Since the incident solar radiation is free, the cost of the electricity from a CSP plant is dependently solely on the depreciation of the initial investment $\operatorname{cost} C_{i n v}$ and the annual plant maintenance cost $C_{O \& M}$. The standard definition of levelised electricity cost (LEC) used in solar thermal calculations [4] is based on the net electrical output $E_{n e t}$ and an annualisation factor $\alpha$, assuming a rate of interest $i$, a payback time $n$ in years and an annual insurance rate $k_{\text {ins }}$. The net electrical output is a function of the total collector area $A_{c o l}$, the incident solar flux $I_{o}$ and three efficiency factors $\varepsilon_{c o l}, \varepsilon_{r e c}$, and $\varepsilon_{c y c}$ for the collector field, solar receiver and power generation cycle respectively.

$$
L E C=\frac{\alpha \cdot C_{i n v}+C_{O \& M}}{E_{n e t}} \text { with } \alpha=\frac{i \cdot(1+i)^{n}}{(1+i)^{n}-1}+k_{\text {ins }} \text { and } E_{n e t}=A_{c o l} \int_{y e a r} \varepsilon_{c o l} \varepsilon_{r e c} \varepsilon_{c y c} I_{o} d t
$$

Any reduction in the LEC will increase the economic competitiveness of the technology and equation (1) brings to light key ways in which reductions can be made:

- The first focus can be placed on reducing the cost of the power plant components (both in term of initial investment $C_{i n v}$, as well as the maintenance $\left.C_{O \& M}\right)$. As the solar field components represent over $50 \%$ of the total investment cost, priority should be placed on reducing the cost of these components. Fortunately, these components are still in the early stages of their learning curve and costs are dropping rapidly.

- A second focus can be placed on increasing the net electrical output $E_{n e t}$ for a given power plant. This can involve optimizing plant design, reducing parasitic consumption as well as improving operational strategy, all of which serve to increase the integrated annual value of $\varepsilon_{c y c}$. 
- The final focus can be placed on new power plant concepts. This can involve moving to more efficient thermodynamic cycles (generally requiring higher temperatures), new receiver designs and improved collector field layouts with the aim of increasing the three efficiencies $\varepsilon_{c o l}, \varepsilon_{r e c}$, and $\varepsilon_{c y c}$ and thus $E_{n e t}$. This can result in lower values of LEC for the plant, as long as the increase in $E_{n e t}$ compensates for any increase in the cost.

\subsection{Reducing Water Consumption}

The deployment of CSP technology is most effective in areas with high direct normal irradiation (DNI). This fact, coupled with the large land requirements for CSP plants would seem to make desert locations very attractive for deployment [1]. However, the high DNI of desert regions comes with a significant draw-back, in that these regions suffer from a severe scarcity of water resources [6] which will place a limit on the number sites found suitable for deployment of this technology.

The current generation of solar thermal power plants, based on conventional steam-cycles, require water for a number of purposes:

- For the cooling of the condenser, with especially large volumes for evaporative cooling

- To replace that lost from the cycle during steam drum blowdown

- To maintain a high efficiency of the solar field: the mirrors need to be kept clean to ensure a high reflectivity

In order to facilitate the increased deployment of solar thermal power in water-scarce areas it will become necessary to reduce the water footprint of CSP plants, shown for a number of contemporary plants in Table 2. A number of options for achieving this have been highlighted:

- Replacing evaporative or once-through cooling systems in steam-cycle power plants with dry or indirect cooling systems, including options for cold-water storage

- Moving towards higher-temperature solar receivers, allowing the use of gas-turbine cycles, eliminating the use of water as a working fluid as well as the need for cooling

- Moving towards high-efficiency power generation cycles, reducing the size of the collector field per unit electrical output, reducing the water use due to mirror washing

Table 2. Water Consumption of contemporary Rankine CSP Plants [8]

\begin{tabular}{cccc}
\hline \multirow{2}{*}{ Power Plant Type } & \multicolumn{3}{c}{ Water Consumption $\left[\mathrm{m}^{3} / \mathrm{MWh}_{\mathrm{e}}\right]$} \\
& Evaporative & Hybrid Dry/Wet & Air Cooling \\
\hline Parabolic Trough & 3.0 & $0.4-1.7$ & 0.3 \\
Solar Power Tower & $1.9-2.8$ & $0.4-1.0$ & 0.4 \\
\hline
\end{tabular}

\subsection{Increasing Availability/Dispatchability of CSP Plants}

The output from a solar thermal power plant is strongly dependent on the available solar flux, which varies due to both the predictable daily evolution of the Sun's position as well as the more unpredictable variations in local weather conditions. This raises two key issues for CSP plants: 
- In order to maintain an acceptable lifetime for the power plant components (turbine, steam generators, etc.) the duration of transient operation should be minimized. To improve the dispatchability of CSP plants, it is also of interest to accelerate the start-up of the turbines in order to bring power rapidly onto the grid once solar energy is available

- In order to increase the flexibility and economic viability of a solar power plant in a liberalised electricity market, it is advantageous for the plant to be able to produce power during times of peak demand, which are not necessarily in phase with times when the solar flux is available.

Both these issues require a decoupling of the energy supplied to the power generation cycle from the incident solar radiation. Over a s hort time period, thermal energy storage can ensure a constant power output to the cycle during solar transients resulting from cloud cover or other meteorological phenomena [2]. Larger storage volumes can also allow dephasing of the electrical output, permitting increased operational flexibility.

At the current time, certain conventional CSP units are built as hybrid plants, using natural gas fired boilers or gas-turbine waste heat recovery boilers for additional steam production when solar radiation is insufficient or absent. With a g as-turbine in the cycle, power production becomes very flexible with the possibility not only to meet peak power demand and to operate at night, but also to reduce the size of the mirror field.

\section{Opportunities for CSP R\&D in Sweden}

Swedish industry is heavily involved in the supply of steam turbines for solar thermal power applications (through Siemens Industrial Turbomachinery) and it can be seen that many of the key opportunities for solar R\&D lie in the field of turbomachinery. As all commercial CSP plants are based on the use of steam-cycle technology, improvements in steam-turbine operational strategy present attractive opportunities for R\&D. Swedish companies such as ABB are involved in supplying tracking systems and others such as Cleanergy supply Stirling engines for solar dish systems.

The challenges presented in $\S 3$ highlight the potential advantages in moving towards gas-turbinebased CSP plants. Use of gas-turbines reduces water consumption and opens the possibility for the use of more flexible hybrid plants as well as higher efficiency combined-cycle systems. Swedish industrial companies are ideally placed to provide gas-turbines in the power ranges suitable for solar thermal applications.

\section{Research focuses at the Department of Energy Technology}

On-going research activities at EGI are focused on responding to the key challenges identified in $\S 3$ as well as supporting Swedish industrial partners in addressing the opportunities created. The following sections present key current projects.

\subsection{Solar Steam Turbine Operation}

Due to the variable nature of the solar supply and the daily operating cycle of solar power plants, the number of turbine starts per year for solar steam turbines is an order of magnitude higher than for base-load turbines. As a result, the speed with which the turbines can be started assumes a 
greater importance in CSP plants and modifications allowing turbines to start faster are examined as part of on-going research.

The speed at which the turbines can reach full load is based on the lowest metal temperature measured before start-up begins. As such, if the steam turbine can be kept hot during idle periods, the duration of the next start-up can be reduced without impacting negatively on the lifetime. A number of modifications that can be made to the turbines to maintain their temperature during idle periods have been evaluated. Heat blankets were shown to be the most effective measure for keeping the turbine casing warm, whereas increasing the gland steam temperature was most effective in maintaining the temperature of the rotor [7]. By applying a combination of these measures the dispatchability of the turbine can be improved significantly: electrical output can be increased by above 9\% for both long and short cool-downs, as is shown in Fig. 3.
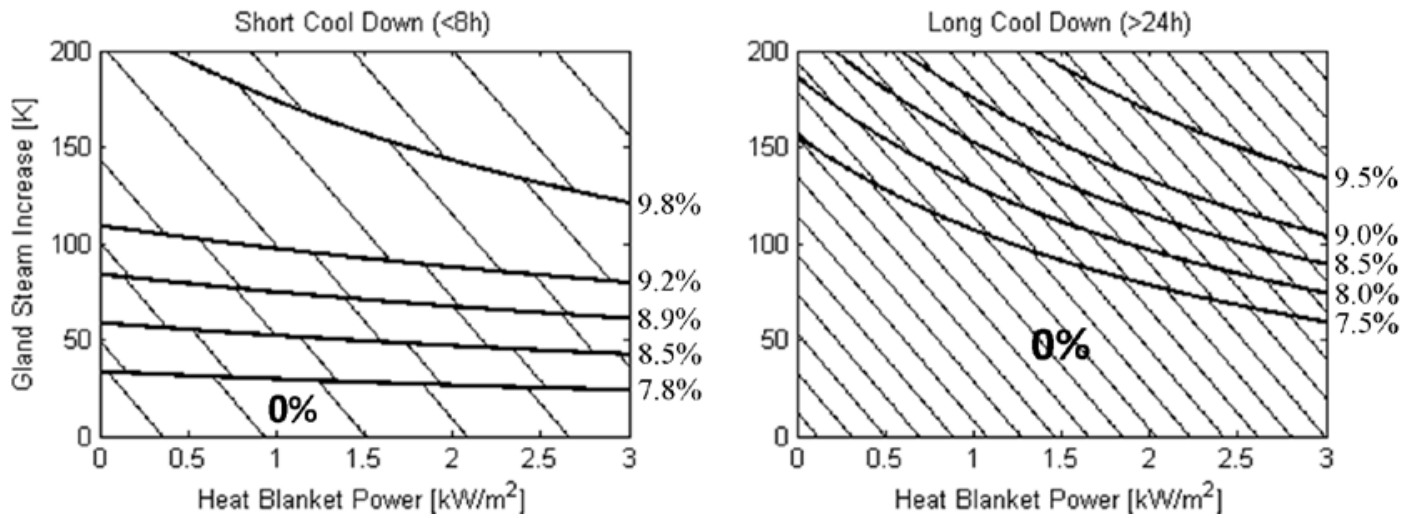

Fig. 3. Impact of applying a combination of heat blankets and gland steam temperature increase on the daily output of the plant on the day following the cool-down period [7]

\subsection{Solar Power Plant Thermo-Economics}

All operational commercial solar thermal power plants are based on the use of Rankine cycles, which are limited in the efficiencies they can achieve by the relatively low temperatures at the receiver. However, developments in the field of high temperature receivers [8] have opened up the possibility to use more advanced thermodynamic cycles, especially the use of gas-turbines. In order to evaluate the potential of new power plant concepts, thermo-economic models are used to predict investment and levelised electricity costs, as well as other important factors such as annual electricity production, water consumption, exergy efficiency, land use and many more [9]. Coupled with a multi-objective optimisation routine, Pareto-optimal power plant designs can be established and the trade-off between economic and environmental objectives analysed. Polygeneration concepts, mainly using waste heat for production of e.g. clean water, cooling or biogas for local consumption can also be positive factors both for acceptance and economy.

\subsection{Solar Receiver Design and Testing for Gas-Turbine Integration}

In order to support on-going solar gas-turbine research at EGI, small-scale but high temperature receivers are being design and tested for use with micro gas-turbines. Availability in Sweden of sunlight strong enough for testing is very limited and therefore a small indoor solar lab has been built, shown schematically in Fig 4. An artificial Sun consisting of strong Xenon lamps produces $11 \mathrm{~kW}$ of radiation which is directed to a parabolic dish of $1.8 \mathrm{~m}$ diameter and used to test small receivers of different innovative designs. Presently two receivers are being investigated: 
- A medium temperature receiver in which materials with high thermal conductivity and coatings for good solar absorption are essential for high efficiency

- A generic high temperature volumetric receiver in which different types of heat exchange materials can be tested both for overall heat transfer data and detailed information on solar penetration depth, temperature gradients, pressure drops, etc.

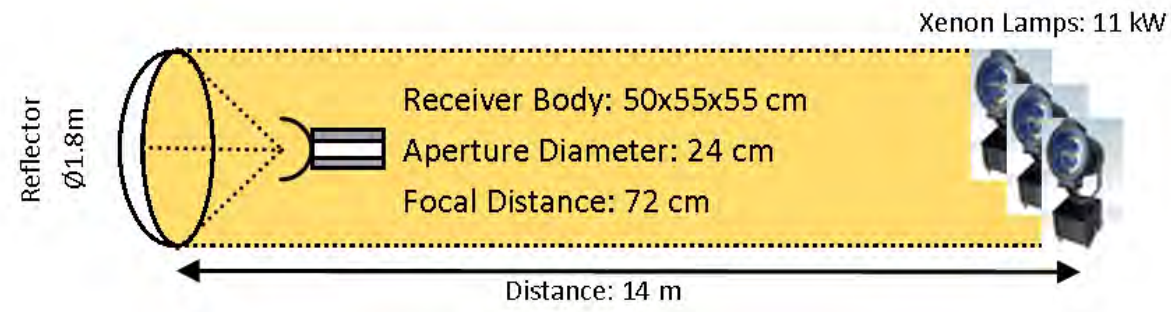

Fig. 4. Basic Layout of EGI's Receiver Test Facility

\section{Conclusion}

Amongst the plethora of renewable energy technologies on of fer, CSP emerges as a promising option for sustainable power generation in the Sun-belt regions of the world. A diverse R\&D community supports the refinement of the technology and commercial CSP plants are beginning to appear worldwide. Swedish industry is well-placed in the market, providing almost the entirety of the steam turbines for conventional CSP plants, as well as a number of ancillary components. Within Sweden, the nurturing of active R\&D is essential to maintain this dominant position. EGI is actively pursuing key issues on different CSP systems such as techno-economic optimization, polygeneration arrangements, receiver components and their integration with the conversion unit.

\section{References}

[1] G. Knies, U. Möller, and M. Straub, "Clean Power from Deserts: The DESERTEC Concept for Energy, Water and Climate Security”, Hamburg, 2007

[2] C. Philibert, "The Present and F uture Use of Solar Thermal Energy as a P rimary Source of Energy", International Energy Agency, Paris, 2005

[3] K. Ummel and D. Wheeler, Desert Power: the Economics of Solar Thermal Electricity for Europe, North Africa, and the Middle East, Center for Global Development, 2008.

[4] R. Pitz-Paal, J. Dersch, and B. Milow, "ECOSTAR: European Concentrated Solar Thermal RoadMapping”, Deutsches Zentrum für Luft- und Raumfahrt, 2004

[5] C. Richter (Editor), "Solar Power and Chemical Energy Systems: Annual Report", Deutsches Zentrum für Luft- und Raumfahrt, Köln, 2008

[6] US Department of Energy, "Reducing Water Consumption of CSP Electricity Generation”, Report to Congress, 2001

[7] J. Spelling, M. Jöcker and A. Martin, "Thermal Modeling of a Solar Steam Turbine with a focus on Start-Up Time Reduction", ASME TurboExpo, Vancouver, 2011

[8] B. Hoffschmidt, F. Tellez, J. Fernandez., "Performance Evaluation of the 200kWth HiTRec-11 Open Volumetric Receiver", Solar Energy Engineering, vol. 125 (2003), pp. 87-97

[9] J. Spelling, D. Favrat, A. Martin et al., "Thermo-Economic Optimisation of Solar Tower Thermal Power Plants", International ECOS Conference, Lausanne, 2010. 